\title{
Research on Natural Ventilation of the Envelope of Green Building Tianqi $\mathrm{Yu}^{1, \mathrm{a}}$, Mengdi $\mathrm{Yue}^{2, \mathrm{~b}}$

\author{
${ }^{1}$ Beijing university of civil engineering and architecture,china \\ ${ }^{2}$ Beijing university of civil engineering and architecture,china \\ ayutianqi@bucea.edu.cn, ${ }^{\mathrm{a}}$ xiaoyuets@163.com
}

\begin{abstract}
Keywords: green building,natural ventilation,space design,structural measures,double skin facade Abstract:Natural ventilation has been an essential building technology for such a long time. As a significant role in the development of architecture design, the natural ventilation was replaced by the development of air conditioning technology for some time. However with the energy crisis and the greenhouse effect, more and more buildings are inclined to the potential of natural ventilation. This research is about how to use the natural ventilation in green building design and divided into three parts respectively: the additional structural measures, space design and the double skin facade.
\end{abstract}

\section{Introduction}

With the rapid development of science and technology and the extraordinary progress of modern society and economy, the design of contemporary architectures that contains material selection, design and the way of self-expression become more and more flexible,so that many people have the higher requirements about their own environment amenity. It is the excessive demands that people hold about their surroundings as well as the untapped constructions that led to the opposition between contemporary architecture and nature being more obvious. A heavy burden was added to all kinds of natural resources and non-renewable energies. At the beginning of the 21 st century, the world energy crisis was broke out in developed countries firstly and the environment problems catch more and more attentions, that highlight the concept of green architecture all over the world. With the progress in construction techniques, the green building design consist of more and more techniques, however the natural ventilation has been proven as a effective method. The air conditioner technology brings people the ability to adjust the indoor micro-climate whether in summer or winter to create a suitable temperature for ourselves. But every coin has it's two sides, the technology of air conditioner brings the decline of air quality, while accompanied with a large number of energy consumption which has become one of the contributor of the greenhouse effect. As a traditional anti-thermal cooling technology, Natural ventilation, by introducing the flow of air naturally to achieve a healthy and effective cooling system to reduce the reliance on air conditioner and mechanical ventilation technology. Natural ventilation is also capable to reduce energy consumption and creates a more healthy and comfortable environment of working and living places and decreases the negative impact of air conditioning technology. Thus we can achieve the purposes of low-carbon, energy saving and environmental protection.

\section{Additional structural measures for natural ventilation}

According to the source of driving force natural ventilation can be divided into tow parts: "the wind ventilation"under the wind-pressing and "the buoyancy ventilation" under the hot-pressing. This section about architectures using additional structural measures for natural ventilation adopts the assortment method between the wind ventilation and the buoyancy ventilation to introduce the combination of natural ventilation and additional structures. 


\section{Additional structural measures about utilizing wind-pressing}

As to the ventilation options of envelope of green building, additional structural measures has always been the most simple and effective way. The familiar structures about using hot-pressing to promote the natural ventilation are ventilation shaft, the air atrium and skylights that can be opened. For example, in Cambridge, UK, the Ionica Telecom headquarters (Fig. 1) is called as a green building which can use energy efficiently. This building uses the Chimney Effect to achieve comfortable natural ventilation. It is designed to allow the inflow of outside air through the opening

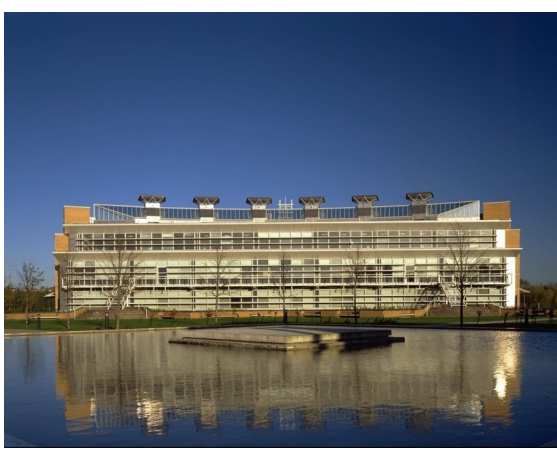
windows instead of the usual way by air conditioning technology. Set up six wind towers at the top of the building to assist air atrium to complete the ventilation task(Fig. 2). Machinery brings air from the bottom of the floor to interior and the opening windows bring air from the outside of the building. When the indoor air is heated which make it lighter than the fresh air, it will exhaust to the outside through the ventilation shaft. These measures are combined together to form a smooth ventilation means, so that the natural ventilation of indoor reached $70 \%$ (Fig. 3 ).

Fig. 1 Ionica Telecom headquarters

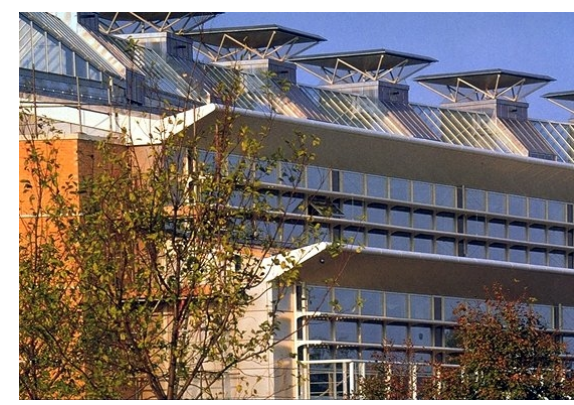

Fig.2 Air shaft on the roof

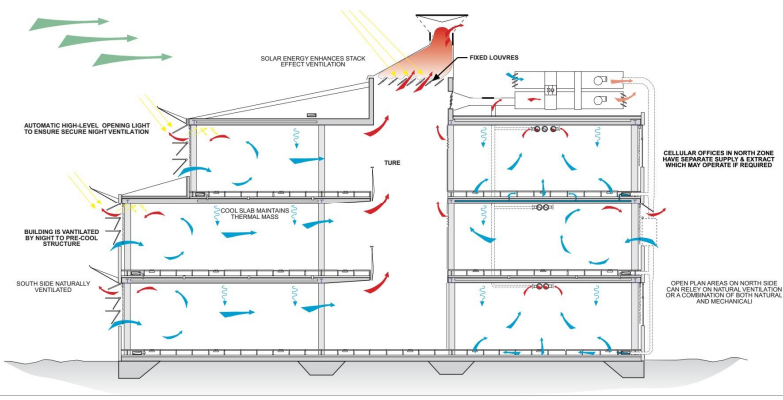

Fig.3 Ventilation analysis of Ioncia

\section{Additional structural measures about utilizing hot-pressing}

There is also a kind of additional structural measures that the natural ventilation forced by wind-pressing acting on the envelope, and the common additional structures of this form are adjustable curtain or adjustable facade of special form. The wind guide system, for example, the Khoo Teck Puat hospital in Singapore. Khoo Teck Puat hospital use a large area of the module shutters and the shutters can change the angle when the external flow changes, thus the building can adjust the air flowing into the ward in a comfortable way. The shutters are set in as high as the hospital bed and when the heavy rain day coming the shutters can guarantee a minimum air exchange(Fig. 4). Khoo Teck Puat hospital also designed to be covered with aluminum alloy radiator in exterior wall known as the "wing wall". When the prevailing winds through the "wing wall", it can effectively increase the pressure of the wind, which playing a guiding role to bring fresh air in the ward (Fig. 5).

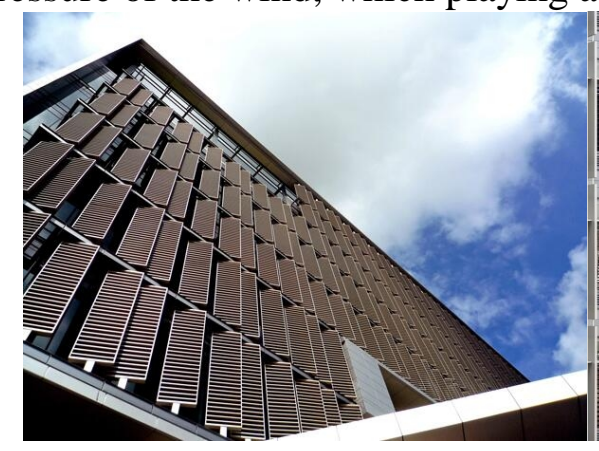

Fig. 4 The module shutter

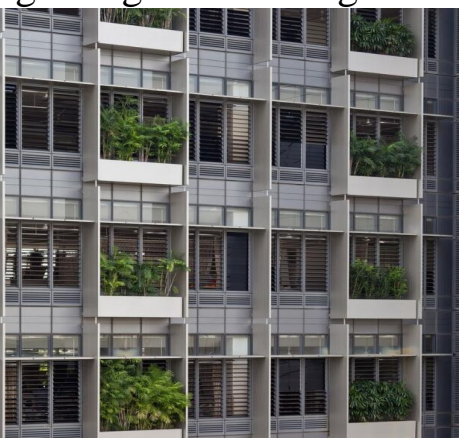

Fig. 5 The wing wall 


\section{Space design for natural ventilation}

The envelope of a building can also combined with space design to achieve a better natural ventilation. According to the combination of envelope and the space, it can be divided into three kinds of ways: interspersion, infiltration and integration.

\section{Space interspersed with the envelope}

The interspersion between integrated skin and space design is a kind of combination between the design of physical space and the design of gray space.The gray space usually use garden. For example, the Hung Hom Bay campus of Hong Kong Polytech University (Fig. 6). The facade design of the campus adopts a series of modular layer. The natural ventilation is promoted by the modular skin which combined with the spiral rising courtyard(Fig. 7, Fig. 8), so that the building reduces the use of air conditioner effectively.The walls of the building that wrapping around the air courtyard use aluminum alloy blinds with different density, the glasses is in different sizes and the traditional university red brick. Many opening windows are adopted by the indoor corridors, that increase the rate of natural ventilation and reduce the power consumption. Such a comprehensive measure provides a natural and comfortable environment for the building and interprets a new concept of learning space.

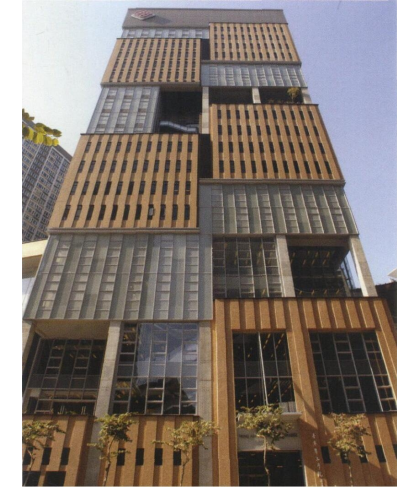

Fig. 6 Building facade

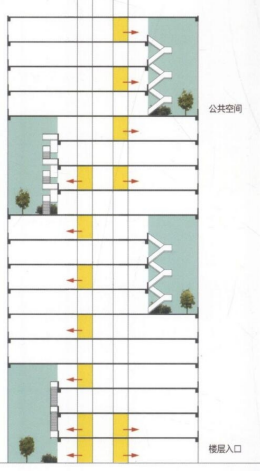

Fig. 7 Building profile

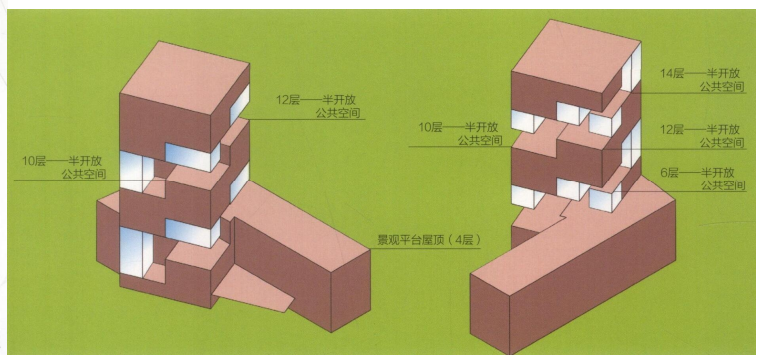

Fig. 8 Building facade

\section{Space integration with the envelope}

The infiltration between the envelope of the building and space design is a method about various of garden space infiltrate into the building gradually. The method gives the courtyard space the ability to flow into the building by a layered way. For example, the Shooting Platform of Beijing Olympic Games. Through the architectural forms about infiltration of Atrium and the "indoor garden" design, the environment is brought in from the outside and the natural ventilation is fully used to achieve a flexible air exchange between indoor and outside door(Fig. 9,Fig 10). In the rest hall of qualification, the atrium is set up through three floors from the bottom to the top. In the first floor of the atrium, the space design combined rest area of athletes with factory booth, further more the design also collocates some green plants and rest corners. Through the establishment of the atrium, the nature light and green plants are brought in the building, and promoting a natural circulation of air. The building finally creating a comfortable, pleasant, green space of human nature (Fig. 11).

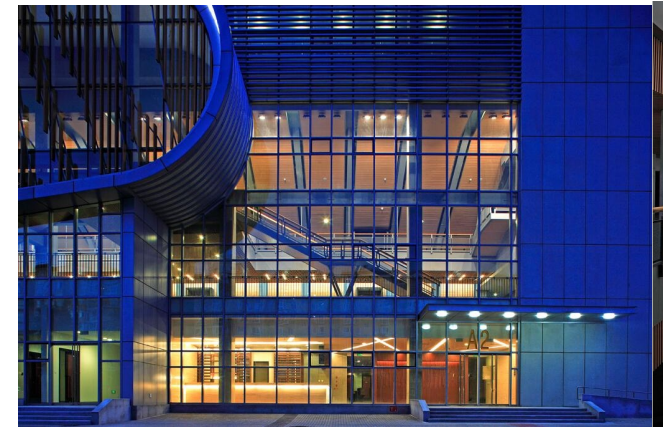

Fig. 9 Part of the hall of Shooting Platform

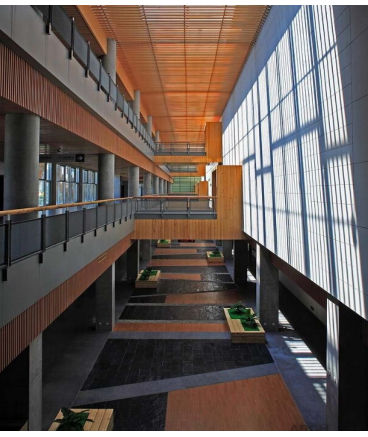

Fig. 10 The atrium of Shooting Platform

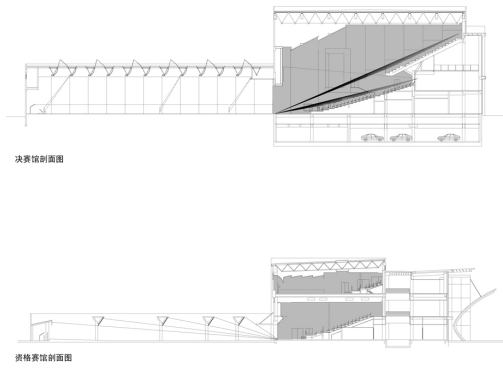

Fig.11 The profile of Shooting Platform 


\section{Space integrate with the envelope}

The integration about the envelope of a building and space design is the indoor garden wrapped with the skin of the building directly. The entrance hall is similar with the formation of greenhouse in which the room space just under an integrated skin. For example, located in Yokohama,Tokyo, The Tokyo Gas headquarters (Fig. 12). Under the integrated skin of the building is a large indoor courtyard, that accounted for nearly half of the distance of the whole depth of the building. There is an opening corridor between the office space and the courtyard. The group effect created by the rising warm air to keep the natural ventilation of the office (Fig. 13). The courtyard brings air from the outside to the base of it, then the air flow through the bottom of the floor and get into the office. When the air warmed up, it get out off the building by the air shaft. The atrium glasses is supported by large and curved wooden strips which form a sealing element. The glasses is covered with a layer of low-emissivity material. The combination between the facade and the large atrium makes the building a percentage of $58 \%$ of the indoor natural ventilation and reach a reduction of energy consumption and environmental protection.

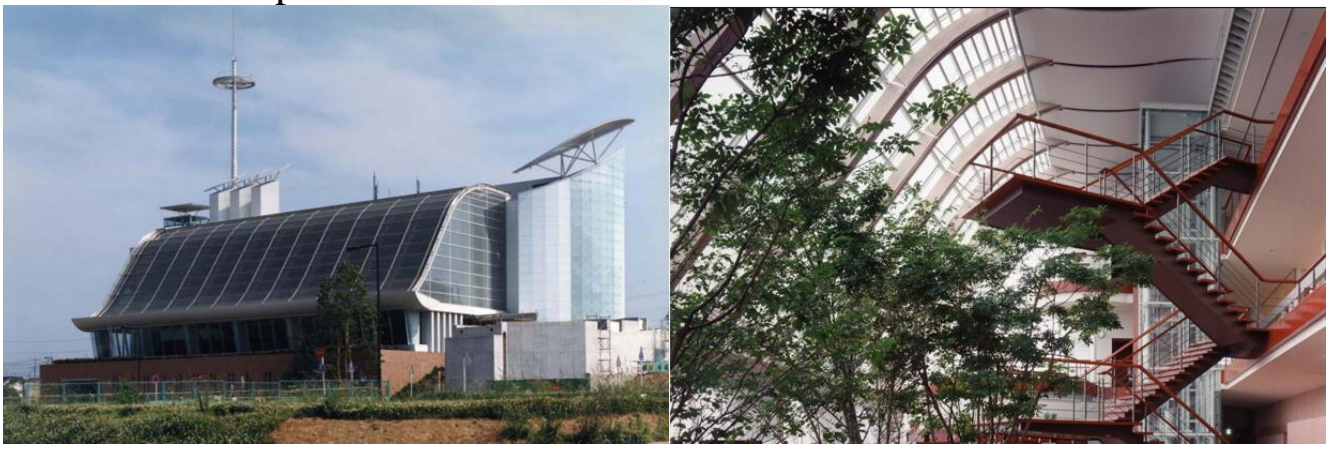

Fig. 12 The Tokyo Gas company headquarters Fig. 13 The hall of the Tokyo Gas

\section{Double skin facade for natural ventilation}

The double skin facade is an exploration for the formation of the single facade with inner shading system. The double skin facade, compared to a single facade, have more advantages in ventilation, shading and energy-saving. This chapter mainly discusses the potential of the double skin facade in natural ventilation, and divide the double skin facade by the ventilation style into tow parts: the outer circulation ventilation and the internal circulation ventilation.

\section{The outer circulation ventilation}

The general structures of the outer circulation ventilation are as follows: the outer facade use fixed single glasses, air inlet and outlet is capable to open and close by electronic way. The inner facade is the real boundary of the building and it usually adopts double glasses. The width of the channel between the two facade is almost 1 meter.

Such as the RWE tower in Essen, Germany, adopts the double skin facade system with 30-storey(Fig. 14). The single strengthened glasses is used in the outer facade and the inner facade adopts insulated glasses, so that the absorption of sunlight is more convenient. The width between the two glasses layers is about $50 \mathrm{~cm}$. All the windows of the office are capable to open and closed, and the percentage of indoor natural ventilation (Fig. 15) is up to 70\%. The integrated components that fixed between the glasses layers is known as the "fish mouth" which have the ability to exchange air. When the air exchanging system is on, each unit of air inlets and outlets that on the facade are remains open, then the internal air is heated and form a temperature gradient to result in the hot-pressing ventilation. The inner glasses layer can be selectively opened or closed according to the demands(Fig. 16). 


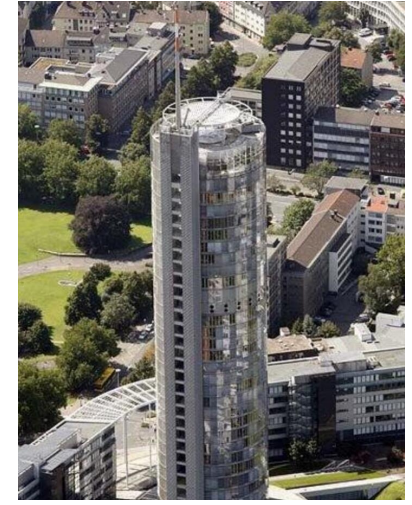

Fig. 14 The RWE tower
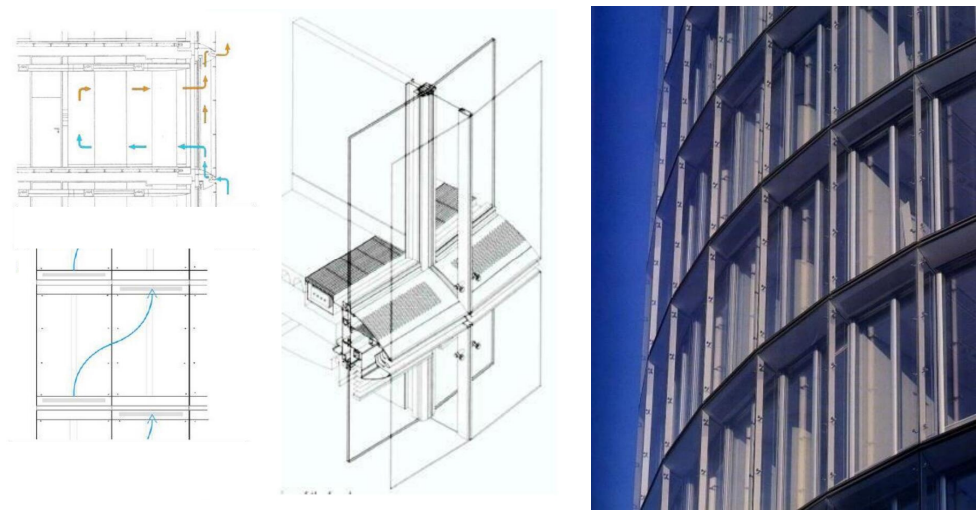

Fig. 16

Part of the facade

\section{The internal circulation ventilation}

The general structures of the internal circulation ventilation are as follows: The outer facade usually can not be opened to ensure the heat preservation. The inner facade adopts the fixed single glasses with air inlets on it. The channel between tow facade is 0.2 meters width more or less. Compared with the outer circulation ventilation, the surface of the inner one can remain the temperature similar to the temperature of the office space, so the indoor comfort can be improved.

For example, located in the Arabia, the Abu Dhabi National Exhibition Center(ADNEC) with 35 floors on the ground and 1 underground floor(Fig. 17). The tower of the building adopts the double skin facade. The double glasses in the outer facade can insulate the heat and the single glasses in the inner facade has the ability to let the sunlight shine into the deep of the building to reduce artificial lighting. Between inner and outer layers, the hollow air layer is the main means of reducing the air temperature in the building. The air layer is also the channel of the cooled air from the air conditioning system. The cool air can flow into the air layer by the grille which is at the bottom of the single glasses and then the cool air absorbs heat to make the temperature of the air rising gradually. The warm air will be exhaust to the outside from the top of the building(Fig. 18).

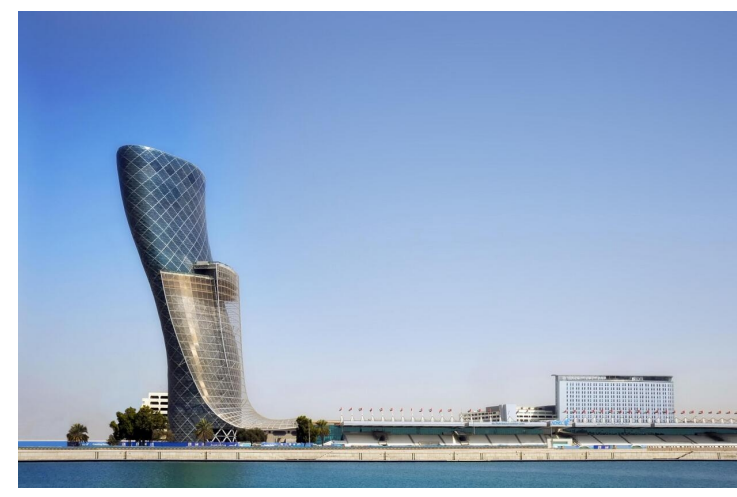

Fig. 17 The ADNEC

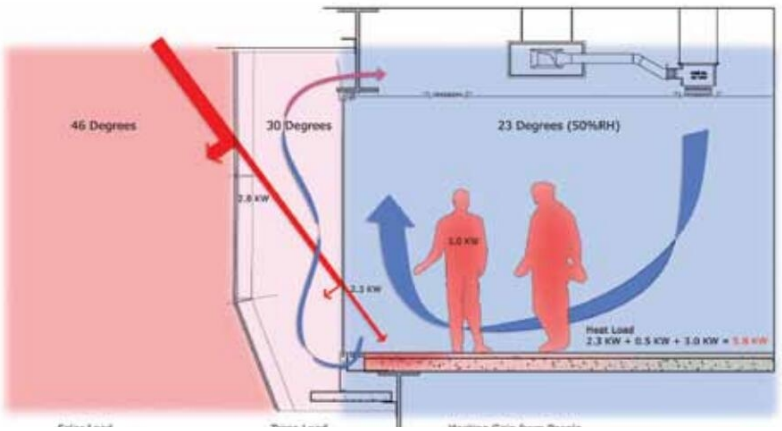

Fig. 18 The ventilation analysis of ADNEC

\section{Conclusions}

In the design of green building, natural ventilation has always been an important aspect and the design of natural ventilation in green buildings will become rich and varied. In this paper, we mainly study the methods about using the hot-pressing and wing-pressing to promote the natural ventilation in the green building by the use of adding structural measures, the space design and the double skin facade. Of course, the process of the natural ventilation design is a system that is part of the ecological system in green building design. The natural ventilation design needs to coordinate with other technical means, such as considering the insulation, shading and other measures, in order to design a building of energy saving, environmental protection and humanization. 


\section{Acknowledgements}

This work was financially supported by Beijing Natural Science Fundation (8154042) and Science and Technology Program of Beijing Municipal Education Commission (KM201410001611).

\section{References}

[1] David Loyd Jones, Architecture an the Environment,translated by Ru Wang, Hongbo Jia, Guoguo Jia, China Architecture \& Building Press, Beijing, 2005.

[2] Xiande Lin, Green Architecture, Chinese Architecture Industry Press, Beijing, 2011.

[3] Weimin Zhuang, Bin Deng and Borong Lin, The Design Strategy of Ecology-Oriented and Environmentally Friendly Architecture Integrated Skin, Chinese Architecture Industry Press, Beijing, 2014.

[4] Xu zeng, Indivadual analysis and study of green building cases,[Master Dissertation], Tianjing University, Tianjing, 2012. 